\title{
Analysis of Customers Acquisition Behaviour of Multiple SIM Networks Among University Lecturers in Southeast Nigeria
}

\author{
Vincent NO. Aghara \\ Department of Marketing, Nnamdi Azikiwe University, Awka, Anambra State, Nigeria \\ E-mail: vn.aghara@unizik.edu.ng
}

Ogwo E. Ogwo

Abia State University, Uturu, Abia State, Nigeria

E-mail: ogwoeogwo@gmail.com

Obinna C. Ojiaku (Corresponding author)

Department of Marketing, Nnamdi Azikiwe University, Awka, Anambra State, Nigeria

E-mail: oc.ojiaku@unizik.edu.ng

Received: Oct. 10, 2018 Accepted: Dec. 7, 2018 Published: April 19, 2019

doi:10.5296/bmh.v7i1.14690 URL: http://dx.doi.org/10.5296/bmh.v7i1.14690

\begin{abstract}
As the voice-service-market of mobile telecommunication providers fast reaches its saturation amidst increasing competition, its revenue potential to telecom providers continue to decline. Therefore, understanding consumers use behavior portends important strategic consideration for customer acquisition and retention for telecom operators. This study seeks to empirically determine the factors that influence the acquisition of multiple GSM networks by university lecturers in Southeastern universities in Nigeria. Data were generated from a sample of 301 respondents. Three hypotheses were stated and tested using Analysis of variance (ANOVA). The result shows positive relationships between income, social affinity networks, and brand image and consumer acquisition of multi SIM networks. It is therefore, recommended that income, social affinity, and brand image be used as strategic marketing tools to attract customers to acquire a particular network.
\end{abstract}

Keywords: brand image, social network, telecommunications, income, GSM, Nigeria 


\section{Introduction}

Globally mobile telecommunication industry has recorded exponential growth in subscriber base since its inception. In Nigeria, the telecommunication sector has experienced growth from a meager 18,724 telephone lines for a population of about 45 million people, as at independence in 1960 to over 160 million active GSM lines for a population of 140 million representing a tele-density of 114.09 (Nigerian Communication Commission, 2017). This translated to a tele-density of about 0.5 telephone lines per 1000 people (Bakare \& Gold, 2011). The exponential growth suggests the success of the liberalization of the telecommunication industry and increased competition in the mobile telephony subsector. The pre-liberalization era was characterized by slow progress, policy inconsistency; the monopoly enjoyed by the then Nigerian Telecommunications Limited (NITEL) and the attendant chaotic and frustrating circumstances. Following the deregulation, five mobile carriers were issued operating license namely MTN, Globacom, Airtel, Etisalat (now 9 mobile) and the defunct M-Tel, and the competitive landscape in the industry has witnessed increased competition in recent years. Despite the competition, consumer dissatisfaction with the quality of service, tariff rates, and network coverage has begun to emerge, as evidenced in the growth of multi-SIM handsets. In other words, consumers now acquire more than one network, and switch between providers in order to enjoy better deals and services as they fluctuate (Ojiaku, Aihie \& Fjellstrom, 2017).

Despite these developments, consumers still experience switching barrier due to the weak mobile number portability regime which was introduced twelve years after the GSM revolution (Ojiaku et al., 2017). Invariably, mobile operators especially the market leader imposed switching cost by charging high tariff rates for off-net calls and low tariffs for on-net calls. These developments suggest that customers would consider their social tie or 'affinity network' among other factors in the consumption of mobile telecommunication services. Evidence suggests that consumers are likely to adopt cellular phones, not just as a business tool, but because of social pressure/social affinity network, as a perceived security device or even as a source of enjoyment (Davis 1993; Kwon, 1994). Furthermore, as the mobile voice service market is fast reaching its saturation and the potential for more revenue to the service providers continue to decline, in the face of unending competition among service providers on the one hand, and consumers continuous search for better service, on the other hand, understanding consumers use behaviour portend important strategic consideration for customer acquisition and retention. Thus, in view of the fact that a consumer must first acquire a particular GSM network before usage; the factors influencing such acquisition should be of strategic importance to the providers. Again, there are four networks of study and the consumer is free to acquire or even drop one or more of the networks. A better understanding of these acquisition factors will enable a provider to stay ahead of the competition.

The objective of this study, therefore, is to empirically determine the factors that influence the acquisition of one or more of the GSM networks. Specifically, the study seeks to examine the extent consumer income, social affinity network and brand image influence the acquisition of multiple GSM. 


\section{Review of Related Literature}

The concept of consumer use behaviour fundamentally reflects the totality of consumers' decisions with respect to the acquisition, consumption, and disposition of goods, services, time and ideas, by human decision-making units over time. According to Hoyer and McInnis (1997), consumer behaviour involves more than just how a person buys products but also includes services, time and ideas. Since consumer use behaviour involves more than just buying, the manner in which consumers buy is extremely important to marketers. Acquisition or buying represents one type of consumer use behaviour and includes other ways of obtaining products and services, such as leasing, trading or borrowing. Typically, consumer acquisition decisions include, but not limited to what, how, when, how much, how often, and even why acquire a particular product or service; and such acquisition behaviour is influenced by cultural, social, personal, and psychological factors.

Acquisition precedes consumption, and product or service usage is at the core of consumer behavior. Hoyer and McInnis, (1997) further stated that usage is at the very core of consumer behaviour. The products we use at particular events may symbolize the importance of such events to us. So, understanding consumers' consumption or usage of products and services, can guide marketing strategy and tactics. For instance, Telecommunications Reports (1995) report that about two-thirds of U.S subscribers use cellular services for personal uses rather than business. James (1992) also reported that while cellular telephones were an important business tool, personal use was the fastest growing sector of the market.

Disposition is about how consumers get rid of an offering they have previously acquired. Again, understanding consumers' disposition behaviour can have extremely important implications for marketers (Jacoby, Berning \& Dietworst, 1997). For instance, by examining general disposition behaviours and German consumers disdain for disposing-of plastics waste, Procter and Gamble were able to develop more conservation-minded packaging (Hoyer \& McInnis, 1997).

\subsection{Conceptual Framework and Hypotheses}

\section{Income}

Consumer income is a function of consumption and savings opportunity gained by an entity within a specified timeframe usually expressed in monetary terms (Schiffman \& Kanuk, 2009). Income for households and individuals is the sum of all the wages, salaries, profits, interests payments, rents and other forms of earnings receive within a given period of time. Consumer income defines consumption possibilities and determines the importance of price or value in customer brand choice. Tomlinson and Warde (1993) opined that income exerts an important influence on consumption patterns, not only because of economic imperatives but also because income is a useful indicator of social class and cultural preferences.

In studying the determinants of willingness to pay for mobile telecommunications services in Nigeria, Oduh and Oduh (2012), posit that the significance of wealth index implies that respondents who earn a higher income, have higher propensity to pay for GSM services, than those with lower income. Invariably, richer household expresses greater willingness for the 
acquisition of mobile telecommunication services. Iqbal (2010) also report that subscribers in low-income countries in Southeast Asia adopt the use of multiple mobile SIMs in order to enjoy on-net call tariffs and benefits. Accordingly, income will affect customers' acquisition of multiple networks.

H1: There is a positive significant relationship between higher income and customer acquisition of multiple GSM networks

\section{Social Affinity Network}

Affinity simply means a strong feeling that one likes and understands someone or something. Asiegbu, Igwe, and Iruka (2012) describe social affinity as the sharing and bonding of a brand in a closed social setting among admirers of the brand. In the context mobile telephony, Motahiri, Mengshoel, Reuthen, Appala, Zoia, and Shah (2012) defined social ties by phone calls made between people by grouping them into various affinity networks, such as family members, friends and co-workers. The authors argued that "affinity network" consists of a group of subscribers in which all of them have a common social tie. This may also apply to calls made within the same network as in the brand community. According to Birke and Swann, (2006), 'network effects' are induced by mobile operators, through the charging of higher prices for off-net calls (i.e., calls put across to a subscriber on a different network) than for on-net calls (i.e., calls put to another subscriber on the same network).

Mobile operators usually adopt a price discrimination regime which favours on-net calls and social affinity networks. Accordingly, it is convenient for a consumer to adopt the same operator of the consumer he/she calls more frequently, which constitutes the relevant reference group that influences his/her choice of an operator (Corrocher \& Zirulia, 2008). Since, mobile telecommunications enable customers to maintain interpersonal relations by bonding family ties and providing frequent connections (Asiegbu et al., 2012), customers use the 'Friends-and-family' calling networks, as part of their cost-saving communication strategies (Iqbal, 2010). Therefore, it is expected that customers' social affinity network will affect the GSM acquisition.

H2: There is a positive and significant relationship between customers'social affinity network and the acquisition of multiple GSM lines.

\section{Brand Image}

Brand image fundamentally is a mental image that reflects the way a brand is perceived, including all the identifying elements, the product or company personality, and the emotions and associations evoked in the consumer's mind (Junaid, Nasreen, Ravichandran \& Ahmed, 2014). Keller (2006) defined brand-image as consumer perceptions of and preferences for a brand, as reflected by the various types of brand associations held in consumers' memory. A positive brand image can be created by the effective use of marketing programmes that link strong, favourable and unique associations to the brand in memory. A successful brand image will enable consumers to identify the needs satisfied by a brand and differentiate the brand from its competitors, and consequently increase the likelihood that consumers will repeat the purchase of the brand (Hsieh, Pan, \& Setiono, 2004). 
Empirical research suggest that a favorable image (i.e. brand, store/retail) lead to loyalty (e.g. Koo, 2003; Kandampully \& Suhartanto, 2000), brand equity (Faircloth, Capella, \& Alford, 2001; Aaker, 1991; Keller, 1993), purchase behavior (Hsieh et al., 2004) and brand performance (Roth, 1995). Similarly, Ogwo and Igwe (2012), find that brand image influences consumer patronage. Ojiaku and Aihie (2018), find a non-significant effect for brand-image on the choice of mobile data service provider. A good brand image, therefore, will effectively position any GSM company ahead of the competition and provide a reason for the brand as the first choice for acquisition.

H3: there is a positive and significant relationship between brand image and acquisition of GSM network

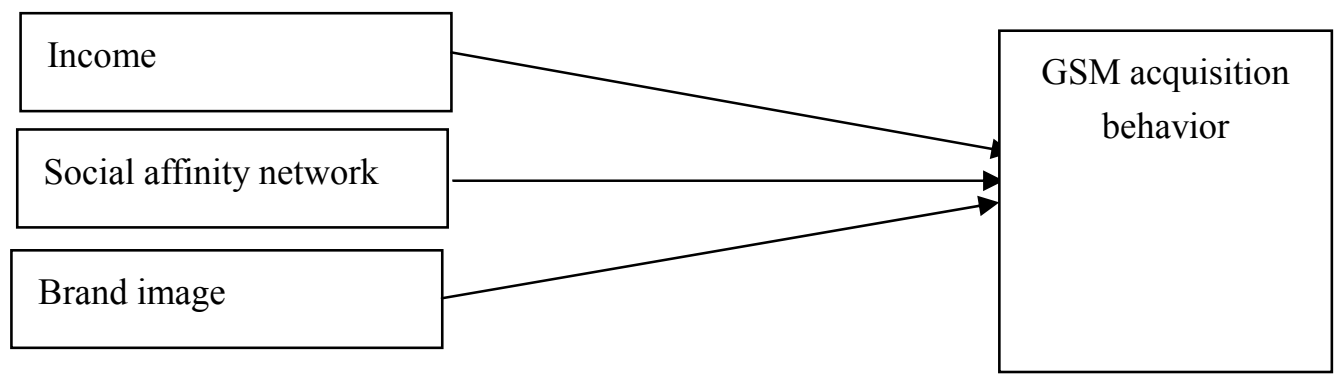

Figure 1. Conceptual model

\section{Method}

This study adopts a quantitative research design. The sample consists of 301 academic staff members from a South-eastern University in Nigeria. The choice of academic staff members is because the group is expected to be knowledgeable about complex issues regarding GSM use behaviour in terms of responses to the quality of data required for the study. The respondents were proportionately selected from the various faculties in the University's main campus based on the population of the faculties. The measurement instrument used was a questionnaire designed to elicit information from the respondents on their GSM use behaviour. The information gathered was useful in answering the generated research questions and equally tested all the hypotheses formulated for the study. Section A of the questionnaire attempted to find out, the effects of respondents' various demographic and other related variables on the choice of GSM network while section B, measured the key constructs in the proposed model of relationships. The measurement instrument consists of 3 items measuring income adapted from themes in the literature, 4 - items measuring social affinity network adapted from Asiegbu et al. (2012) and, 4 items measuring brand image adapted from Faircloth et al. (2001). All items were measured on 5 points Likert scale from 5 strongly agree to 1 - strongly disagree. The dependent variable was measured using open-ended and closed-ended questions eliciting responses on the first GSM acquired, and subsequent GSM acquired. The validity test was conducted by subjecting the instruments to scrutiny by very experienced senior and middle-level academic staff. 


\section{Results}

\subsection{Demographic Profile of Respondents}

The respondents are split with male representing $53.8 \%$ of the respondents while $46.2 \%$ of the respondents are female. The age of the respondents shows that about $69 \%$ of the respondents are less than 40 , while $24.5 \%$ are between $40-49$ years indicating that most of the lecturers are young. More than $60 \%$ of the respondents have a post graduate degree $(52.4 \%$ M.Sc and 9\% Ph.D.) while 37.2\% have a B.Sc degree. The Gross Income of the respondents shows that $36.2 \%$ of the respondents earn between 100,000 and 200,000 (Nigerian naira), $26.2 \%$ earn between 200,001 and 300,000 and only 7\% earn above \$400,001 (Nigerian naira). For GSM profile, $78 \%$ of the respondents acquired and used MTN as their first GSM, 14.5\%acquired Globacom, 8\% acquired and used Airtel and Etisalat respectively as their first GSM. Whereas for Second GSM 21.7\% of the respondents use MTN, while 31\%, 23.1\% and $24.1 \%$ of the respondents use GLO, Airtel, and Etisalat respectively. Similarly, responses from respondents on the GSM they acquired and used for data services shows that $35.7 \%$ used MTN, Globacom 10.8\%, Airtel 26.5\%, and Etisalat 27\% respectively. Furthermore, a cross-tabulation was performed between the age of respondent and first GSM acquired, Age and Second GSM acquired and Age and GSM acquired for data use. The result showed that 98 respondents between 31 and 39 acquired MTN as their First GSM, while 42 of the respondents who fall between 31 and 49 acquired GLO as their first GSM. Whereas Etisalat and Airtel were only used by 8 of the respondents each of whom fall between $40-49$ age brackets. The summary of the demographic data is shown in table 4.1 below.

The reliability result shows that the measurement items are internally consistent for the social affinity network and brand image Cronbach alpha $=0.81$ and 0.76 respectively (Benchmark $>$ 0.70; Nunnally \& Bernstein, 1994). The reliability test for Income as an independent variable below fell below the acceptable region (Income alpha=0.400). However, alpha is highly dependent on the number of items in the proposed scale (Morgan et. al. 2014). Thus, an $($ alpha $=0.69)$ should be marginally acceptable for a two-item scale.

Table 1. Demographics of respondents and GSM profile

\begin{tabular}{llll}
\hline Variables & Options & Frequency & Percentage (\%) \\
\hline Gender & Male & 156 & 53.8 \\
Age & Female & 134 & 46.2 \\
& 30 or less & 92 & 31.7 \\
& $31-39$ & 109 & 30.4 \\
\multirow{2}{*}{ Education } & $40-49$ & 71 & 24.5 \\
& $50 \&$ Above & 18 & 6.2 \\
& B.Sc & 108 & 37.2 \\
& M.Sc & 152 & 52.4 \\
& Ph.D & 26 & 9 \\
& Others & 4 & 1.4 \\
\hline
\end{tabular}




\begin{tabular}{|c|c|c|c|}
\hline Ma & $\mathbf{e}^{T M}$ & & $\begin{array}{r}\text { Business and Management Horizons } \\
\text { ISSN 2326-0297 } \\
\text { 2019, Vol. 7, No. } 1\end{array}$ \\
\hline \multirow[t]{3}{*}{ Marital Status } & Single & 168 & 57.9 \\
\hline & Married & 119 & 41 \\
\hline & Separated & 3 & 1 \\
\hline \multirow[t]{5}{*}{ Gross Income } & 100,000 and Below & 105 & 36.2 \\
\hline & $100,001-200,000$ & 76 & 26.2 \\
\hline & $200,001-300,000$ & 46 & 15.9 \\
\hline & $300,001-400,000$ & 38 & 10.6 \\
\hline & $400,001 \&$ above & 25 & 7.0 \\
\hline \multirow[t]{5}{*}{ First GSM } & MTN & 228 & 78.6 \\
\hline & GLO & 42 & 14.5 \\
\hline & Airtel & 8 & 2.8 \\
\hline & Etisalat & 8 & 12.8 \\
\hline & Others & 4 & 4 \\
\hline \multirow[t]{4}{*}{ SECOND GSM } & MTN & 63 & 21.7 \\
\hline & GLO & 90 & 31 \\
\hline & Airtel & 67 & 23.1 \\
\hline & Etisalat & 70 & 24.1 \\
\hline \multirow[t]{4}{*}{ DATA GSM } & MTN & 66 & 35.7 \\
\hline & GLO & 20 & 10.8 \\
\hline & Airtel & 49 & 26.5 \\
\hline & Etisalat & 50 & 27.0 \\
\hline
\end{tabular}

\subsection{Test of Hypotheses}

To test the hypotheses, an ANOVA was performed using SPPS version 17 with income, brand image and social affinity network as independent variables and GSM acquisition as the dependent variable. The result shows that a statistically significant difference was found between higher income and acquisition of multiple GSM networks, F $(9,280)=23.08, \mathrm{p}=.00$. The results support the stated hypothesis that higher Income has a positive and statistically significant relationship with Multiple GSM acquisition. Thus, consumers with higher Income can afford Additional GSM and the income budget of consumers will determine their GSM brand Acquisition. It can be concluded therefore that a statistically and positive relationship exists between income and acquisition of multiple GSM networks. Thus, Hypothesis 1 is supported. Hypothesis 2 sought to find out if there was any relationship between Social Affinity of the respondents and the acquisition of multiple GSM networks. The result shows that a statistically significant relationship exists between consumers with social affinity network and acquisition of multiple GSM networks, F $(9,280)=13.023, p=.00$. Therefore, hypothesis 2 is supported and it can be concluded that a statistically significant relationship exists between consumers' with wide social affinity network and acquisition of multiple GSM networks. Finally, the third hypothesis sought to determine the nature of the relationship between the provider's image and the network acquired by the respondents. The result shows a statistically significant relationship between brand image and acquisition of multiple GSM networks, $\mathrm{F}(9,280)=18.81, \mathrm{p}=.00$. Therefore, hypothesis 3 is supported and it can be 
concluded that network providers' brand image will significantly affect the use of multiple GSM networks. The summary of the result is shown in table 2 below.

Table 2. Univariate test for multiple GSM acquisition

\begin{tabular}{lllllll}
\hline & & Sum of Squares & df & Mean Square & F & Sig. \\
\hline Income & Between Groups & 109.468 & 9 & 12.163 & 23.089 & .000 \\
& Within Groups & 147.501 & 280 & .527 & & \\
Social affinity network & Between Groups & 53.353 & 9 & 5.928 & 13.023 & .000 \\
& Within Groups & 127.461 & 280 & .455 & & \\
Brand image & Between Groups & 157.510 & 9 & 17.501 & 18.806 & .000 \\
& Within Groups & 260.576 & 280 & .931 & & \\
\hline
\end{tabular}

\section{Discussion and Conclusion}

This study examines customers' acquisition of GSM for pre-paid voice services. The result confirms findings from previous studies on the effect of higher income on consumer behaviour (Oduh \& Oduh, 2012) but contradicts Iqbal (2010). The findings suggest that the income level of customers will determine the acquisition of multiple GSM network. Despite that, customers acquire multiple SIMs and often run parallel accounts to take advantage of better deals and cost-savings from mobile operators, maintaining a subscription and keeping the accounts active involve considerable budget which thus would necessitate the need for a high income. The income distribution from our data set shows that more than $60 \%$ of the respondents earn above 100,000 naira, this is a plausible explanation of the significant effect of income on the acquisition of multiple GSM. Therefore, as income increases, consumers would acquire additional GSM.

Furthermore, the significant effect of social affinity network on multiple SIM acquisition confirms the findings of Asiegbu et al. (2012). The finding lends support to the argument that consumers acquire multiple SIM to save cost by calling mobile numbers on the same network and taking advantage of on-net call rates. Therefore, consumers acquire multiple GSM networks, because they wish to maintain contact with their friends and affinity group, as well as with others, who use different networks. Also, social class appreciation and special services offered by networks are additional attractions. This finding is consistent with Igwe and Ogwo (2012), which suggests that there is a relationship between social affinity and intention to use a particular network. Finally, the significant effect of brand image confirms previous studies by Ogwo and Igwe (2012) but contradicts Ojiaku \& Aihie (2018). The findings suggest that customers' favourable perception of brands and corporate social responsibility efforts of the brand affects customers' decision to subscribe to mobile services with such a brand.

From the foregoing, it is evident that there is a positive relationship between consumers' income, social affinity, and acquisition of multiple networks. This implies that that income 
and social affinity influence consumers' acquisition behaviour in the marketplace. Acquisition of multiple GSM networks has the implication of encouraging patronage switching among providers, which makes it difficult to unduly exploit the potentials of each customer value. In addition, the study also revealed a positive relationship between brand image and choice of network, suggesting that a brand with a favourable image is most likely to attract and retain the patronage of her customers. It is then concluded that income and social affinity positively affect acquisition of multiple GSM lines. In addition, the positive perception of brand image affects the choice of network provider which encourages the acquisition and retention of the services of such service provider.

\section{Managerial Implications}

The implication of the findings for management is that management of telecom companies should consider it worthwhile to adopt specific marketing strategies aimed at improving their network/brand image. Such specific strategies should include, but not limited to community relations and good corporate social responsibility (CSR), all aimed at emphasizing exceptional managerial prowess targeted at the consumers' perception of the network. Furthermore, since most GSM telecommunication companies have a number of products that encourage social affinity network effect, it becomes imperative that such strategies are strictly sustained. In addition, promotional strategies should be targeted at the various social affinity network groups of customers, to encourage the development of brand communities and reinforces customer brand attachment.

\section{Limitation and Suggestion for Further Studies}

The study is not without its limitations. The sample of the academic staff of a Southeastern University limits the generalization of the findings. Future studies can include other consumer groups. Second, the perspective taken in this study is the voice service perspective for pre-paid customers, it will be interesting to investigate mobile data service viz-a-viz the voice service with respect to customer acquisition of GSM networks and incorporating other variables which may also affect consumer behaviour in the context of mobile telephony. Finally, this study used ANOVA to test the hypotheses. Future studies may consider using statistical techniques that are more robust such as the multiple regression analysis or structural equation modelling.

\section{References}

Aaker, D. A. (1991). Managing brand equity: Capitalizing on the value of a brand name. New York: The Free Press.

Asiegbu, I. F., Igwe, S. R., \& Iruka, C. H. (2012). Antecedents of intention-to-use a particular mobile service among South-South University Lecturers in Nigeria. International Journal of Business and Social Science, 3(19).

Bakare, A. S., \& Gold, K. L. (2011). Estimating the impacts of Global System for Mobile Telecommunication (GSM) on income, employment and transaction cost in Nigeria. Journal of Economics and International Finance, 3(1), 37-45. 
Birke, D., \& Swann, P. G. M. (2005). Network effects and the choice of mobile phone operator. Journal of Evolutionary Economics, 16(1-2), 65-84. https://doi.org/10.1007/s00191-005-0001-5

Corrocher, N., \& Zirulia, L. (2008). Me and you and everyone we know: An empirical analysis of local network effects in mobile communications. Rimini Centre for Economic Analysis, Rimini, Italy.

Davis, D. M. (1993). Social impact of cellular telephone usage in Hawaii. In J. G. Savnge \& D. J. Wedemeyer (Eds.), Pacific Telecommunications Conference Proceedings (Vol. II, pp. 641-648). Honolulu, HI: Pacific Telecommunication Conference.

Faircloth, J. B., Capella, L. M., \& Alford, B. L. (2001). The effect of brand attitude and brand imageon brand equity. Journal of Marketing Theory and Practice, 9(3), 61-74. https://doi.org/10.1080/10696679.2001.11501897

Hoyer W. D., \& MacInnis D. J. (1997). Consumer Behaviour, Boston. Houghton Mifflin Company.

Hsieh, M. H., Pan, S. L., \& Setiono, R. (2004). Product-, corporate and, and purchase behavior: A multi-country analysis. Journal of the Academy of Marketing Science, 32(3), 251-270. https://doi.org/10.1177/0092070304264262

Iqbal, T. (2010). Mobile Number Portability in South Asia. https://doi.org/10.2139/ssrn.1618182

Jacoby, J., Berning C. K., \& Dietworst. (1997). "What about disposition"? Journal of Marketing, (April), 22-28.

James, M. C. (1992). Cellular phones and highway safety. Legislative Reference Bureau, State of Hawaii.

Junaid, A. B., Nasreen, R., Ravichandran, N., \& Ahmed, F. (2014). Indian Cosmeceutical Market: A study of consumer preferences and consumption patterns. Journal of Clinical Experimental Dermatology Research, 5(2), 1-8. https://doi.org/10.4172/2155-9554.1000212

Kandampully, J., \& Suhartanto, D. (2000). Customer loyalty in the hotel industry: The role of customer satisfaction and image. International Journal of Contemporary Hospitality Management, 12(6), 346-351. https://doi.org/10.1108/09596110010342559

Keller, K. L. (1993). Conceptualizing, measuring, and managing customer-based brand equity. Journal of Marketing, 57(1), 1-22. https://doi.org/10.1177/002224299305700101

Keller, K. L. (2006). Strategic brand management: Building, measuring and managing brand equity (2nd ed.). New Delhi, Pearson Educational, Inc.

Koo, D. M. (2003). Inter-relationships among store images, store satisfaction, and store loyalty among Korea discount retail patrons. Asia Pacific Journal of Marketing and Logistics, 15(4), 42-71. https://doi.org/10.1108/13555850310765033 
Kwon H. S. (1994). “The Social Impact of Cellular Telephones in Honolulu”. CIS Working Paper, University of Hawaii.

Motahari, S., Mengshoel, O.J., Reuthen, P., Appala, S., Zoia, L., \& Shah, J. (2012). The impact of social affinity on phone calling patterns: categorizing social ties from calldata records. In proceeding of the 6th SNA-KDD Workshop (SNA-KDD'12), August 12, 2012, Beijing, China.

NCC, Report. (2017). Quarterly Summary of Telecoms Subscribers in Nigeria.

Nunnally, J. C., \& Bernstein, I. (1994). Psychometric theory (3rd ed.). New York, NY: McGraw-Hill.

Oduh, M. O., \& Oduh, M. O. (2012). Determinants of willingness to pay for mobile telecommunications services in Nigeria. Journal of Information Engineering and Applications, 2(6), 33-42.

Ogwo, E. O., \& Igwe, S. R. (2012). Some key factors influencing attitudes to the patronage of GSM services: The Nigerian experience. International Journal of Business and Management, 7(18), 82-91. https://doi.org/10.5539/ijbm.v7n18p82

Ojiaku, O. C., \& Aihie, O. (2018). Determinants of customers' brand choice and continuanceintentions with a mobile data service provider: The role of past experience. Global Business Review, 19(6), 1-16. https://doi.org/10.1177/0972150918780764

Ojiaku, O. C., Aihie, O., \& Fjellstrom, D. (2017). Determinants of customers' intention to 'port' mobile phone numbers in times of proliferating use of multi-SIMs. International Journal of Applied Business and Economic Research, 15(22), 621-643.

Roth, M. S. (1995). Effects of global market conditions on brand image customization and brand performance. Journal of Advertising, 24(4), 55-72. https://doi.org/10.1080/00913367.1995.10673489

Schiffman, L. G., \& Kanuk, L. L. (2009). Consumer Behavior (9th ed.). Pearson Prentice Hall International Edition: New Jersey.

Tomlinson, M., \& Warde, A. (1993). Social class and change in eating habits. British Food Journal, 95, 3-10. https://doi.org/10.1108/00070709310023413

\section{Copyright Disclaimer}

Copyright for this article is retained by the author(s), with first publication rights granted to the journal.

This is an open-access article distributed under the terms and conditions of the Creative Commons Attribution license (http://creativecommons.org/licenses/by/4.0/). 